\title{
Prognostic value of pre-treatment routine hematological parameters in breast carcinoma: Advantageous or deleterious?
}

\author{
Manigatta Doddagowda Shilpa ${ }^{1,}{ }^{*}$, Raju Kalyani ${ }^{1}$, P N Sreeramulu${ }^{2}$
}

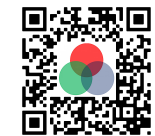

Use your smartphone to scan this QR code and download this article

${ }^{1}$ Department of Pathology, Sri Devaraj Urs Medical College, Sri Devaraj Urs Academy of Higher Education \& Research Tamaka, Kolar -563101, Karnataka, India

${ }^{2}$ Department of Surgery, Sri Devaraj Urs Medical College, Sri Devaraj Urs Academy of Higher Education \& Research Tamaka, Kolar -563101, Karnataka, India

\section{Correspondence}

Manigatta Doddagowda Shilpa Department of Pathology, Sri Devaraj Urs Medical College, Sri Devaraj Urs Academy of Higher Education \& Research Tamaka, Kolar -563101, Karnataka, India

Email: drkalyanir@rediffmail.com

\section{History}

- Received: May 292020

- Accepted: Jul 262020

- Published: Aug 312020

DOI : 10.15419/bmrat.v7i8.621

\section{Check for updates}

\section{Copyright}

(๑) Biomedpress. This is an openaccess article distributed under the terms of the Creative Commons Attribution 4.0 International license.

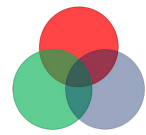

\begin{abstract}
Introduction: The most common malignancy which endangers the quality of life in females is breast cancer. It is also the major public problem in society and despite advances in treatment strategies, it still leads to high mortality. In all breast cancer patients, the first assessment done before surgery is the complete blood count (CBC). There exists a strong relationship between immune response of the body and clinical staging of breast cancer. This study aimed to determine the most reliable hematological markers for the prognosis of breast cancer, and to evaluate the correlation between hematological parameters and disease staging. Methods: This study was a case control study conducted for a period of 3 years from Jan 2016 to December 2018 in the Department of Pathology (R.L.Jalappa hospital and Research Center attached to Sri Devaraj Urs medical college, Tamaka, Kolar, Karnataka). The comparison of the hematological parameters was done between the study group (70 cases) and the control group (20 cases). The relation between the hematological parameters and the various stages of breast cancer was analyzed before initiating the treatment. Results: The majority of the breast cancer patients were of stage 2 . The hemoglobin concentration, red blood cell (RBC) count, lymphocyte count, and hematocrit were reduced in the study group, with a significant difference $(p<0.05)$ when compared to the controls. Hemoglobin concentration, RBC count, hematocrit, white blood cell (WBC) count, and absolute lymphocyte count were inversely proportional to the stage of breast cancer. The absolute neutrophil count, neutrophilto-lymphocyte ratio (NLR), and platelet-to-lymphocyte ratio (PLR) were directly proportional to the progression of disease. Conclusion: Hemoglobin, RBC count, WBC count (including differential count), NLR, and PLR are the key hematological indicators which predict the severity and mortality risk of breast carcinoma.
\end{abstract}

Key words: Inflammation, NLR, PLR, Prognostic markers

\section{INTRODUCTION}

The second most common carcinoma among females is breast cancer, with a prevalence of $99 \%$ and also the commonest malignancy which affects half a million women worldwide each year. Annually, in more than $1,000,000$ cases of females, the cause of death is breast cancer ${ }^{1}$.

According to the cancer registry data, the incidence of carcinoma of the breast ranges from 19.3 to 89.7 per 100,000 population (India), with a total of $27.5 \%$ cases of cancers in Karnataka ${ }^{2}$. The prevalence of carcinoma of the cervix in Kolar, Karnataka amounts to $17.6 \%$ of all cancer cases in the female population. Squamous cell carcinoma accounts for $80 \%$ of cases while adenocarcinoma is relatively rare ${ }^{3}$. In spite of the improvement in therapies, the mortality rate of cancer is still increasing. Recently, there has been growing interest in investigations on the functions of the immune system in progression and cessation of tumor growth ${ }^{4,5}$.
The importance of the immune system in progression of malignancies has been investigated. Hematological parameters like red cell indices, leukocyte count, mean platelet volume (MPV), and platelet counts have shown their prognostic importance in different types of malignancies. The routinely performed investigations before, during and after cancer treatment is the complete blood count $(\mathrm{CBC})$, which roughly estimates the patient's anemic, nutritional, inflammatory and immunologic status. The neutrophil-tolymphocyte ratio (NLR), which has been used as a biomarker of inflammation, can also be useful as a prognostic index for various common solid tumors, such as nasopharyngeal cancer, gastric cancer, colorectal carcinoma, breast carcinoma and malignant melanoma. In addition, the NLR has been used as a simple marker of systemic inflammatory response in cancer patients. Similarly, pre-operative platelet-tolymphocyte ratio (PLR) has also been suggested as a significant factor to predict survival in pancreatic can$\operatorname{cer}^{5,6}$. 
All kinds of diseases and cancers that vary in terms of disease progression have a direct influence on hematological parameters. Breast cancer also shows its effect on hematological parameters and also helps in predicting the outcomes of patients with breast can$\mathrm{cer}^{7}$. Therefore, there is a need for simple, lowcost, reliable and non-invasive prognostic inflammatory biomarkers which will be helpful for clinicians to perform risk evaluation in breast carcinoma patients before or during the treatment process.

This study, therefore, aimed to determine the most reliable hematological markers for the prognosis of breast carcinoma and to evaluate the relationship between hematological parameters and stage of cancer.

\section{MATERIAL AND METHODS}

This study was a case control study for a period of 3 years. The study was started after obtaining the approval from the ethics committee (R.L.Jalappa hospital and Research Center attached to Sri Devaraj Urs medical college, Tamaka, Kolar, Karnataka). The study group (70 cases) included female patients who were diagnosed with breast cancer. The demographic data (such as age, menstrual history, parity, history of any previous surgery, clinical presentation, and hematological parameters were obtained from patient medical records. Hematological parameters were compared between the study and the control groups. Analysis of these parameters with the staging of the breast cancer was done prior to the initiation of any treatment, such as surgery, radiotherapy or chemotherapy.

Breast cancer patients were staged clinically according to the tumor, node and metastasis (TNM) classification. Hematological parameters included hemoglobin, red blood cell (RBC) count, mean corpuscular volume (MCV), mean corpuscular hemoglobin $(\mathrm{MCH})$, mean corpuscular hemoglobin concentration (MCHC), and white blood cell (WBC) count. All the parameters were estimated using a 5-part Sysmex automated cell analyzer which works on the principal of volumetric impedance and photometric measurement of light absorbance. Neutrophil-to-lymphocyte ratio (NLR) and platelet to lymphocyte ratio (PLR) were also calculated based on the CBC. The NLR was calculated by dividing the absolute neutrophil count and absolute lymphocyte count; cut-off value taken was $\leq 2.21$ (area under ROC curve, 0.617; 95\% confidence interval). The PLR was calculated by dividing the platelet count and absolute lymphocyte count; the cut-off value was $\leq 143.36$ (area under the ROC curve, 0.618; 95\% confidence interval) ${ }^{8}$.
The control group (20 cases) included female patients diagnosed with benign breast disease. The inclusion criteria were patients with breast lumps who had a diagnosis of breast carcinoma by Fine Needle Aspiration Cytology (FNAC) and confirmed by histopathology. The exclusion criteria included breast carcinoma patients who had an infection at the time of sample collection, had undergone neoadjuvant chemotherapy or radiotherapy, and had any other type of malignant lesions.

\section{Statistical analysis}

The data obtained were statistically analyzed using the SPSS software version. Mean \pm standard deviation was used to express the results; Chi square test was used wherever necessary. The parameters with $\mathrm{p}<$ 0.05 were considered to be significant.

\section{RESULTS}

A total of 90 cases of breast disease were analyzed, out of which 70 cases were of breast carcinoma and 20 cases were of benign breast disease. Out of the 70 cases of breast carcinoma, the maximum of cases were seen in stage 2 , followed by stage 3 , stage 1 and stage 4 , respectively (Table 1 ).

Table 1: Number of cases with stage and age distribution of the patients in the present study

\begin{tabular}{lcc}
\hline Disease type & $\begin{array}{c}\text { Number of } \\
\text { cases }\end{array}$ & $\begin{array}{c}\text { Age } \\
(\text { Mean } \pm \text { SD) }\end{array}$ \\
$\begin{array}{l}\text { Control } \\
\text { group }\end{array}$ & 25 & $31 \pm 10$ \\
Study group & 70 & \\
Stage 1 & 11 & $45 \pm 8$ \\
Stage 2 & 28 & $44 \pm 12$ \\
Stage 3 & 22 & $39 \pm 15$ \\
Stage 4 & 09 & $48 \pm 13$ \\
\hline
\end{tabular}

All the hematological parameters of the study group were compared with the control group. It was observed that the haemoglobin concentration, RBC count, haematocrit and lymphocyte count were reduced in the study group when compared to the controls, with a significant difference $(\mathrm{p}<0.05)$. However, the RBC indices (MCV, MCH and MCHC), WBC count, neutrophil count and platelet count did not show any significant correlation (Table 2).

The hematological parameters were also compared with the different stages of breast cancer (Table 3 ). 
The hemoglobin concentration, RBC, hematocrit, WBC count, and absolute lymphocyte count decreased with disease stage. There was no significant change in RBC indices and absolute neutrophil count. The platelet count was directly proportional to the staging of breast cancer. NLR and PLR showed significant increases in Stage 4 when compared to stage 1.

\section{DISCUSSION}

Complete blood count (CBC) is a useful basic investigation performed routinely in all cancer patients before, during and after treatment. Various hematological parameters can be measured by this investigation; alterations in any of the parameters further helps to investigate the underlying causes so that treatment can be planned accordingly ${ }^{7,9}$. Hence, it is important to also investigate breast cancer patients prior to initiation of any treatments like surgery, radiotherapy and/or chemotherapy. In the current study, we analyzed all the hematological parameters in breast carcinoma patients and found notable variations.

In the present study, the hemoglobin concentration showed a mean of $9.8 \mathrm{~g} / \mathrm{dl}, \mathrm{RBC}$ count of $3.98 \mathrm{x}$ $10^{6} / \mathrm{mm}^{3}$, and hematocrit of $31.8 \%$, when compared to the control group. The majority of the cases had a normocytic normochromic blood picture. Our study correlated significantly with previous studies which showed decreased hemoglobin with normocytic normochromic blood picture. Chronic diseases and cancers can cause decreased production of erythropoietin which in turn leads to decreased production of RBC, resulting in anemia. The other possible causes may be due to low socioeconomic status causing nutritional anemia and metastasis of cancer cells to bone marrow, leading to suppression of all the hematological cell series $^{7,10}$. It was also noted that as the stage increased, all these parameters decreased.

The RBC indices did not show any significant correlation with the control group nor also with the different stages of breast carcinoma. The mean total leukocyte count did not show any significant correlation with the control group but as the disease progressed from stage 1 to stage 4 , the count decreased. The total leukocyte count is greatly affected by increase or decrease of neutrophils, eosinophils, lymphocytes, monocytes and basophils ${ }^{11}$. In the present study, the absolute neutrophil count did not show any significant correlation with the control group nor also with staging.

There was a decrease in the absolute lymphocyte count in the present study, with an increase in staging of the breast cancer and severe lymphocytopenia noted in stage 4 . These findings are comparable to studies done by Rana APS et al. ${ }^{12}$ and Parkin DM et al. ${ }^{13}$, who observed that the decrease in lymphocyte count was proportional to progression of disease. The mechanism of tumor immunity is mainly carried out by $\mathrm{CD}^{+}$cytotoxic $\mathrm{T}$-cells which mediate killing of tumor cells and which are capable of destroying tumor cells prior to sensitization. Hence, a decrease in these cells causes suppression of tumor immunity and poor prognosis ${ }^{12}$. Higher peripheral blood CD8 ${ }^{+}$ count with higher survival was reported in a study conducted by Lee et al. ${ }^{14}$.

The mean platelet count, even though it was higher in the study group, did not show any significant correlation with that of the control group; however, the increase in platelet count was directly proportional to the staging of the breast cancer. Systemic inflammation leads to release of several pro-inflammatory mediators, which stimulate megakaryocyte proliferation, such as interleukin (IL)-1, IL-3 and IL-6. Many studies have shown that the higher mortality is associated with elevated platelet count in several cancers. Thus, innate antitumor responses through cellinduced platelet aggregation is modulated negatively by platelets which shields tumor cells from the major histocompatibility complex so as to escape immune surveillance by $\mathrm{T}$ cells ${ }^{14,15}$.

In the current study, there was an increase in the NLR as the disease progressed. The NLR ratio was found to be higher in patients with axillary lymph node metastasis. Many studies have shown that a pre-operative increase in the NLR ratio suggests poor prognosis of the breast cancer patients; it can be used as an independent prognostic factor in breast carcinoma ${ }^{11,16}$. The process for elevated NLR is explained by relative increase in the neutrophil count and relative decrease in the lymphocyte count, causing the breakdown of balance in the tumour microenvironment. Cellular immune responses decrease as a consequence to lymphocytopenia and there is an increase in the inflammatory response. This increase in inflammation causes an increase in tumor growth, invasion and metastasis $^{11,15,16}$. The usefulness of the NLR in predicting short- and long-term mortality in breast cancer patients was first evaluated by Azab et al. ${ }^{17}$.

A meta-analysis study showed the association of NLR with the prognosis of the breast cancer (i.e., the higher the values, the shorter the survival time for diseasefree survival (DFS) and overall survival (OS), and the poorer the prognosis ${ }^{11,18}$.

The present study also demonstrated that increase in pre-operative PLR was significantly associated with the disease progression and axillary lymph node 
Table 2: Comparison of haematological parameters in control and study group

\begin{tabular}{|c|c|c|c|}
\hline Test & Control group & Study group & P-Value \\
\hline Hemoglobin concentration $(\mathrm{g} / \mathrm{dl})$ & $11.4 \pm 3.8$ & $9.8 \pm 2.2$ & $<0.05$ \\
\hline $\mathrm{RBC}\left(\mathrm{x} 10^{6} / \mu \mathrm{l}\right)$ & $4.8 \pm 0.6$ & $3.98 \pm 0.7$ & $<0.05$ \\
\hline Haematocrit (\%) & $35.4 \pm 3.6$ & $31.8 \pm 5.5$ & $<0.05$ \\
\hline MCV (fL) & $82.2 \pm 5$ & $80.6 \pm 6$ & 0.010 \\
\hline $\mathrm{MCH}(\mathrm{pg})$ & $26.2 \pm 4.2$ & $25.6 \pm 3.6$ & 0.1 \\
\hline $\mathrm{MCHC}(\mathrm{g} / \mathrm{dl})$ & $33.37 \pm 1.02$ & $32.85 \pm 1.83$ & 0.08 \\
\hline $\mathrm{WBC}\left(\mathrm{x} 10^{3} / \mu \mathrm{l}\right)$ & $6.35 \pm 4.8$ & $7.1 \pm 1.8$ & 0.22 \\
\hline Neutrophil count (\%) & $48 \pm 7.2$ & $65 \pm 12.7$ & 0.22 \\
\hline Platelet count $\left(\mathrm{x} 10^{3} / \mu \mathrm{l}\right)$ & $235.7 \pm 93.2$ & $248 \pm 90.8$ & 0.99 \\
\hline Lymphocyte count (\%) & $35.03 \pm 8.29$ & $20.91 \pm 2.25$ & $<0.05$ \\
\hline
\end{tabular}

Table 3: Comparison of the haematological parameters with the different staging of breast cancer

\begin{tabular}{|c|c|c|c|c|}
\hline Parameters & Stage 1 & Stage 2 & Stage 3 & Stage 4 \\
\hline $\begin{array}{l}\text { Hemoglobin concentration } \\
(\mathrm{g} / \mathrm{dl})\end{array}$ & $10.94 \pm 1.27$ & $9.42 \pm 0.78$ & $9.1 \pm 1.97$ & $8.44 \pm 1.28$ \\
\hline $\mathrm{RBC}\left(\mathrm{x} 10^{6} / \mu \mathrm{l}\right)$ & $4.95 \pm 0.90$ & $3.5 \pm 0.44$ & $3.0 \pm 0.86$ & $2.9 \pm 0.8$ \\
\hline Hematocrit (\%) & $33.8 \pm 3.14$ & $30.6 \pm 7.7$ & $28.4 \pm 2.0$ & $25.6 \pm 2.5$ \\
\hline $\operatorname{MCV}(f l)$ & $82.8 \pm 6.7$ & $80.8 \pm 4.5$ & $79.4 \pm 3.2$ & $78.9 \pm 2.5$ \\
\hline $\mathrm{MCH}(\mathrm{pg})$ & $25.2 \pm 4.3$ & $26.2 \pm 4.2$ & $26.78 \pm 2.1$ & $26.78 \pm 1.1$ \\
\hline $\operatorname{MCHC}(\mathrm{g} / \mathrm{dl})$ & $32.1 \pm 3.95$ & $30.5 \pm 2.1$ & $32.1 \pm 0.8$ & $30.8 \pm 1.0$ \\
\hline $\mathrm{WBC}\left(\mathrm{x} 10^{3} / \mu \mathrm{l}\right)$ & $7.7 \pm 2.8$ & $6.9 \pm 1.9$ & $5.7 \pm 1.7$ & $3.9 \pm 1.1$ \\
\hline Absolute Neutrophil count & $6,502 \pm 1226$ & $5,323 \pm 936$ & $6,240 \pm 813$ & $5,470 \pm 6,36$ \\
\hline Platelet count $\left(\mathrm{x} 10^{3} / \mu \mathrm{l}\right)$ & $250.2 \pm 93.1$ & $262.5 \pm 85.2$ & $287.2 \pm 84$ & $298.7 \pm 90$ \\
\hline Absolute Lymphocyte count & $2,825 \pm 925$ & $2,432 \pm 623$ & $1,956 \pm 840$ & $1,784 \pm 5.77$ \\
\hline NLR & $2.1 \pm 1.25$ & $2.4 \pm 1.08$ & $2.8 \pm 1.10$ & $3.2 \pm 1.77$ \\
\hline PLR & $90.84 \pm 35.33$ & $107.60 \pm 42.06$ & $146.72 \pm 40.36$ & $150.30 \pm 50.36$ \\
\hline
\end{tabular}

metastasis; these results are in accordance to the study done by Takeuchi $\mathrm{H}$ et al. ${ }^{15}$. The mechanism is due to the platelets which play an important role in tumor progression and to lymphocytes which have a major role in immunosurveillance which suppresses tumor maturation ${ }^{15}$. Hence, an elevated PLR in patients with cancer is associated with lymph node metastasis and can be considered as a poor prognostic marker.

\section{CONCLUSION}

Complete blood count impacts the response of cellular immunity on any cancer patient; alterations in any of the hematological parameters shows a high impact on disease progression. Our study showed that the hematological parameters like hemoglobin, RBC count, hematocrit, WBC count, platelet count, absolute neutrophil count, absolute lymphocyte count, NLR and PLR in breast cancer can be a useful guide for disease progression. They can also be advantageous for helping oncologists decide on how to provide further treatment. The increase in NLR and PLR values can be deleterious to cancer patients as those values are associated with poor prognosis and higher mortality.

\section{ABBREVIATIONS}

CBC: Complete blood count

RBC: Red Blood Cell 
WBC: White Blood Cell

MCV: Mean Corpuscular Volume

MCH: Mean Corpuscular Hemoglobin

MCHC: Mean Corpuscular Hemoglobin Concentra-

tion

NLR: Neutrophil to Lymphocyte Ratio

PLR: Platelet to Lymphocyte Ratio

DFS: Disease free survival

OS: Overall survival

\section{ACKNOWLEDGMENTS}

Not applicable.

\section{AUTHOR'S CONTRIBUTIONS}

Dr. Shilpa.MD: Concept design, collection of data, review of literature, case collection, statistical analysis, interpretation of the results and preparing manuscript. Dr. Kalyani.R: Concept, editing and review of manuscript. Dr. PN.Sreeramulu: Case collection, editing manuscript.

\section{FUNDING}

Not applicable.

\section{AVAILABILITY OF DATA AND MATERIALS}

Data and materials used and/or analyzed during the current study are available from the corresponding author on reasonable request.

\section{ETHICS APPROVAL AND CONSENT TO PARTICIPATE}

The study was started after obtaining the approval from the ethics committee (R.L.Jalappa hospital and Research Center attached to Sri Devaraj Urs medical college, Tamaka, Kolar, Karnataka).

\section{CONSENT FOR PUBLICATION}

Not applicable.

\section{COMPETING INTERESTS}

The authors declare that they have no competing interests.

\section{REFERENCES}

1. Khan S, Khoso SA, Memon S, Adeel A, Nabi G. Study of some Haematological parameters as Biomarker for breast Cancer population of Sindh. Sindh Univ Res Jour. 2017;49(1):23-28.

2. National Cancer Registry Programme, Indian Council of Medical Research. Leading sites of cancer. In, Consolidated Report of Population Based Cancer Registries 2012- 2014, Incidence and Distribution of Cancer. Bangalore: Coordinating Unit, National Cancer Registry Programme (ICMR). 2016;14:8-30.
3. Kalyani R, Das $S$, Singh MSB, Kumar HML. Cancer profile in Kolar: A ten years study Indian J Cancer. 2010;47(2):160165. PMID: 20448380. Available from: https://doi.org/10.4103/ 0019-509X.63011.

4. Smita S, Masamatti I, Vijaya C. Hematological parameters in pre chemotherapy breast cancer patients in a tertiary care centre. Journal of Diagnostic Pathology and Oncology. 2018;3(3):237-240. Available from: https://doi.org/10.18231/ 2581-3706.2018.0049.

5. Arslan C, Aksoy S, et al. Increased mean corpuscular volume of erythrocytes during capecitabine treatment: A simple surrogate marker for clinical response. Tumori. 2011;97:711716. PMID: 22322836. Available from: https://doi.org/10.1177/ 030089161109700606.

6. Zhang $\mathrm{P}$, Zong $\mathrm{Y}$, Liu $\mathrm{M}$, Tai $\mathrm{L}$, et al. Prediction of outcome in breast cancer patients using test parameters from complete blood count. Molecular and Clinical Oncology. 2016;(4):918924. PMID: 27284423. Available from: https://doi.org/10.3892/ mco.2016.827.

7. Al-arifi AA, Kumar A, Chigurupati S, Jawed M, Pandurangan T. Pretreatment variations in haematological parameters of breast cancer patients. International Journal of Pharmacy and Pharmaceutical Sciences. 2018;10(2):157-161. Available from: https://doi.org/10.22159/ijpps.2018v10i2.23669.

8. Kin HY, Kim TH, Yoon HK, Lee A. The Role of Neutrophil lymphocyte ratio and platelet lymphocyte ration in predicting neoadjuvant chemptherapy response in breast cancer. Journal of breast cancer. 2019;22(3):425-438. PMID: 31598342. Available from: https://doi.org/10.4048/jbc.2019.22.e41.

9. Olufemi AE, Saliu OA, Layiwola AM, Olayide AS. Haematological parameters in female breast cancer patients in south western Nigeria. Int J Med Health Sci. 2013;2(4):398-401.

10. Poggiali E, Amicis MM, Motta I. Anemia of chronic disease: a unique defect of iron recycling for many different chronic diseases. Eur J Intern Med. 2014;25:12-17. PMID: 23988263. Available from: https://doi.org/10.1016/j.ejim.2013.07.011.

11. Chen L, Kong X, Yan C, Fang Y, Wang J. The research progress on the prognostic value of the common haematological parameters in Peripheral venous blood in breast cancer. Onco Targets and Therapy. 2020;13:1397-1411. PMID: 32104003. Available from: https://doi.org/10.2147/OTT.S227171.

12. Rana APS, Kaur M, Zonunsanga B, Puri A, Kuka AS. Preoperative Peripheral blood count in breast carcinoma: Predictor of prognosis or a routine test. International Journal of Breast cancer. 2015;2015:1-5. PMID: 26697229. Available from: https://doi.org/10.1155/2015/964392.

13. Parkin DM, Bray EL, Ferlay J, Pisani P. Estimating the world cancer burden. Globocon 2000. International Journal of Cancer. 2001;94(2):153-156. PMID: 11668491. Available from: https://doi.org/10.1002/ijc.1440.

14. Lee YTN. xPeripheral lymphocyte count and subpopulations of $\mathrm{T}$ and $\mathrm{B}$ lymphocytes in benign and malignant diseases. Surgery gynecology and obstretics;144(3):435-450.

15. Takeuchi H, Fukuyama S, Kubo N, Kubo N, et al. The Prognostic Signoficance of the preoperative Platelet-Lymphocyte Ratio in Japanese Patients with Localized Breast Cancer. Advances in Breast Cancer Research. 2016;5:49-57. Available from: https://doi.org/10.4236/abcr.2016.52005.

16. Elyasinia F, Keramati MR, Ahmadi F, et al. NeutrophilLymphocyte ratio in different stages of breast cancer. Acta Med Iran. 2017;55(4):228-232.

17. Azab B, Bhatt VR, Phookan J, Murukutla S, Kohn N, Terjanian $T$, et al. Usefulness of the neutrophil-to-lymphocyte ratio in predicting short- and long-term mortality in breast cancer patients. Ann Surg Oncol. 2012;19:217-224. PMID: 21638095. Available from: https://doi.org/10.1245/s10434-011-1814-0.

18. Ethier JL, Desautels D, Templeton A, Shah PS, Amir E. Prognostic role of neutrophil to lymphocyte ratio in breast cancer: a systemic review and meta-analysis. Breast Cancer Res. 2017;19(1):2. PMID: 28057046. Available from: https://doi.org/ 10.1186/s13058-016-0794- 1. 